\title{
Working with Different Text Types in English and Arabic: Translation in Practice
}

BAHAA-EDDIN HASSAN. (ed.). 2019. Working with Different Text Types in English and Arabic: Translation in Practice, Cambridge Scholars Publishing: UK.

Reviewed by RAMESH M. INGALE

Working with Different Text Types in English and Arabic: Translation in Practice is an edited book by Bahaa-eddinHassan. The book is primarily written for student community. The book has six chapters of which first three, namely, Basic Concepts, Legal Texts and Scientific and Medical Texts are contributed by Hassan and the last three, Media and Political Texts, Translating News, and Technical Texts are contributed by Svetlana Tyutina, Kais A. Kadhim, and Klara Garamszegi, namely. Each text has its own structure, language, style and content. The book brings out the various strategies of language while translating these different text types. The chapters are divided into suitable sections with numbers and bold type to make the reading easy to understand. Every contributor of the book has tried his best to support his/her argument with number of examples from different texts such as legal, scientific, medical, media, political and technical. Sample questions, footnotes and bibliography are given wherever necessary at the end of the chapter. The editor, Bahaa A Hassan is a linguist with Ph.D.in pragmatics and translation from South Valley University, Egypt. Among other contributors, Svetlana V. Tyutina is Ph. D. in Romance Linguistics from Harzen State Pedagogical University, Petersburg and in Spanish from Florida International University, Miami, Florida. Kais Kadhim is Ph.D. in Linguistics from University of science, Malaysia. Klara Garamszegi is M.A. in English, Hungarian and Professional Translation from the University of Sciences, Babes-Bolyai. 
The italics used in this review are by the reviewer's or otherwise mentioned separately.

The first chapter, Basic Concepts begins with the definition of translation. Hassan says that translation is a text-based activity and therefore the strategies used in translation depend upon the text. In this way, the title of the text and translation activity are linked which helps to make the title clear to the readers. The first paragraph clearly brings out the intention of the book as to shed light on the translation of miscellaneous texts. Learning objectives are given for the students so as to help them to know what they will understand after reading the book. There is a reference to Halliday's division of register into field, tenor and mode to make it clear that language changes according to register i.e. use/subject matter. Difference between register and style/register and genre is explained. The writer gives explanation regarding what type of knowledge a translator should possess to perform his duty honestly.

The second chapter Legal Texts deals with the discussion of legal texts in which features of legal language are explained as technical terminology, formulaic deictic expression, long and complex sentences, and grammatical constructions. Examples of all these features are given with explanation to make the terms clearer to the readers. The binding line between the source and the target text is equivalence. Therefore, working with legal texts, a translator follows many translation strategies to meet standards of equivalence. The writer also explains two types of equivalence as formal equivalence-rigid adherence to the form of source language and functional equivalence complete disregard for the form of the source language. Strategies used by legal translator are explained as modulation, shift, over-translation (addition), under-translation, (omission) substitution, expansion, exoticism and creation. The book has become special as it abounds in examples which prove the 
point. To explain these translation strategies, there are samples of civil documents as well as international document like the agreement between the governments of the state of Quwait and the Government of Romania on visa exemption. This is presented in Arabic source text and in English as its target text. Under UN document, there is an example of Universal Declaration of Human Rights in English and its Arabic translation as target text. To make his point clearer, the writer has provided gloss items in English and Arabic corresponding to the text with his comments.

The third chapter Scientific and Medical Texts begins with introduction of some common features of scientific and medical language as simple structure and sentence ordering, explicitness, objectiveness and impersonality. The writer argues that there are some direct translation strategies used in translating such as borrowing or transliteration which means a word taken from one language to another, claque or loan translation which means a kind of semantic translation, gloss translation which aims at rendering the terms and concepts into target language by translating the lexicon, communicative translation in which a translator attempts to give the exact contextual meaning of the original in such a way that content and form are readily acceptable and comprehensible to the readers. This section of the book has become very much meaningful as the writer has given a lot of examples from English and Arabic scientific and medical texts/pamphlets to support his argument. According to the writer, translation of scientific and medical texts is all about terminology. This terminology gives these texts the fuel to convey the information. The writer also brings out that medical terminology often has words with prefixes and suffixes from Latin and Greek. 
The fourth chapter Media and Political Texts is contributed by Svetlana Tyutina. It starts with reference to technical aspects of media and political texts. Writer's argument is that language of a political text has a more rigid structure. To prove the point, writer has cited the definition of a political text by Krisztina Sarosi-Mardirosz. According to Krisztina, political language uses terminology which is related to political philosophy. The present chapter deals with linguistic challenges in media and political texts and suggests means to face them. It is seen that political texts have their peculiar aspects. These aspects are stylistic, structural, syntactic, pragmatic, cultural and lexical. These aspects are further explained with suitable examples to support the argument. Some questions based on texts are given for the readers to answer them. The chapter makes a reference to one distinctive feature of media and political text as compression. Compression is the tendency to transmit as much information in as short a form as possible. Various types of compression and its sub-types are given with examples. These types of compression are structural, phonetic, semantic and pragmatic. The chapter ends with conclusions, exercises and bibliography.

The fifth chapter Translating News is contributed by Kais Kadhim. The chapter begins with the reference to the terminology of the political text as the special language of politics and political theory. It is used to build the relationship between the individual and society. In this context, there is a reference to characteristics of political language given by Sarosi Mardirosz. These are persuasion, reasoning and deceit. The writer gives some strategies used while translating news. These are modulation, shift, over-translation, undertranslation, substitution, expansion, exoticism, updating, situational equivalence, and creation. Questions are given to check the understanding of the readers which the writer refers as quizzes. Samples of texts in the form of exercises are given 
in English and Arabic so as to help the readers to understand the process of translation from ST to TT and vice versa. The readers are asked to translate some underlined words in the texts or they are asked to suggest better translation of these words. There are exercises given to translate the text from English into Arabic and vice versa. The chapter ends with questions on translation strategies and bibliography.

The last chapter, Technical Texts is contributed by Klara Garamszegi. In academic circles, technical translation is considered as (Byrne 2006) the ugly duckling of translation but it has its own attributes/features. The chapter begins with reference to the features of technical texts. These are logical sequence of utterances, domain-specific terminology, specific sentence patterns, passive constructions, general pronoun 'we', third person style and abstract nouns. There is a reference to A. J. Herbert's practical manual; The Structure of Technical English which gives some frequently used formulae in technical texts. These formulae are given in a tabular form which helps the readers to understand the nature of technical language. Some of the examples of these formulae are IT IS + ADJ + TO INFINITIVE or IT IS + ADJ + THAT CLAUSE. (Capital letters by the writer) The main features of technical style are given by referring to Knittlova Damgar. These features are strictly logical syntax, sentence ordering, explicitness, objectiveness, impersonality, lack of emotional load and condensation. Logical sentence order is achieved by the translator by using linking elements like thus, however and in addition etc. (italics by the writer). The writer suggests that a technical translator must have a career background and high level of knowledge of the subject and relevant scientific and technical terminology. He must be aware of the fact that the primary objective in technical style is functionality which is a pragmatic aspect. For the better understanding of the readers, the writer gives number of samples/examples of technical texts 
from various technical fields where features of technical language are shown in bold and the terms are underlined. To name a few of these fields are oil and gas safety procedures, petroleum industry, liquid waste management, ethanol production etc. Gloss in English and Arabic is given. This is followed by bibliography and information about the contributors.

The nature of the book is that there is a possibility of overlapping. In chapter second, Legal Texts, the writer, Hassan gives the strategies used like modification, shift etc. which are used in translation of legal documents. The same strategies are repeated in chapter five, Translating News, written by K. Kadhim. At the same time, the presentation style of these strategies is different in both the chapters. In chapter two; these are given in bold type and at the centre of the page. However, in the fifth chapter, they are not in bold and are placed to the left side. This may harm the total unity of presentation of the book. Moreover, in chapter four, Media and Political Texts, contributed by Svetlana, begins with the subpoint 4.1 as Technical Aspects of Media and Political Texts while the fifth chapter, Translating News, also begins with sub-point 5.1 as Technical Aspects of Political Texts. Credit must be given where it is due. Writers of the book have made use of a number of references which are mentioned in the bibliography. However, in chapter six, on page no. 124, while explaining the importance of terminologies in translation of technical texts, writer uses a quote in double inverted commas. It is not made clear as whose words these are, as writer says, "To conclude a technical translator's task is to keep consistent terminology in technical translation, as well as the very formulaic and repetitive nature of technical writing". The editor of the book should have given an introductory note or preface to make the viewpoint clear. 
The most striking feature of this book is that it provides lot of examples in each chapter. Therefore, it is a very useful course book for students and teachers who want to take up translation from English into Arabic and vice versa. The writers have tried to incorporate theory and practice of translation. The book explains various strategies used in translating different types of texts. All the six chapters in the book are composed in a lucid and easy to read language. Overall, the book clarifies many key concepts of translation in a simple and user-friendly way. It will definitely prove a good reader for the students.

\section{References}

BYRNE, JODY. 2006. Technical Translation Usability Strategies for Translating Technical Documentation. Springer. Dordrecht. 